06

\title{
Литий-ионный суперконденсатор с положительным электродом на основе углеродного материала, модифицированного полимерным комплексом никеля с основанием Шиффа
}

\author{
(C) Ю.А. Положенцева, М.П. Карушев ", А.М. Румянцев, И.А. Чепурная, А.М. Тимонов \\ Физико-технический институт им. А.Ф. Иоффе РАН, Санкт-Петербург, Россия \\ ๑ E-mail: mkarushev@mail.ioffe.ru
}

Поступило в Редакцию 14 ноября 2019г.

В окончательной редакции 21 ноября 2019 г.

Принято к публикации 22 ноября 2019 г.

\begin{abstract}
Впервые разработан литий-ионный суперконденсатор с положительным электродом на основе высокопористого углеродного материала, модифицированного электронопроводящим полимерным комплексом никеля с основанием Шиффа. Электрохимическая емкость полученного устройства более чем на $40 \%$ превысила емкость ячейки с немодифицированным положительным электродом при сохранении остальных практически значимых характеристик (рабочего напряжения, сопротивления, количества циклов заряда-разряда).
\end{abstract}

Ключевые слова: литий-ионный суперконденсатор, проводящий металлополимер, основание Шиффа, удельная объемная емкость.

DOI: 10.21883/PJTF.2020.04.49052.18113

В настоящее время ведутся активные работы по созданию новых типов накопителей электрической энергии, характеризующихся высокой энергоемкостью, мощностью и эксплуатационным ресурсом. Одним из примеров подобных накопителей является литий-ионный суперконденсатор - гибридный источник питания, полученный путем комбинации положительного электрода двойнослойного суперконденсатора и отрицательного электрода литий-ионного аккумулятора. Литий-ионный суперконденсатор превосходит по энергоемкости двойнослойный суперконденсатор, а по мощностным характеристикам - литий-ионный аккумулятор, что потенциально делает его устройством выбора в различных областях практического применения (от портативной электроники до интеллектуальных сетей электроснабжения) [1-3].

Одним из основных направлений совершенствования литий-ионного суперконденсатора является поиск путей увеличения емкости его положительного электрода, так как именно она определяет емкость конечного устройства. Для изготовления положительного электрода используются главным образом различные высокопористые углеродные материалы, традиционно применяющиеся в качестве электродов в двойнослойных суперконденсаторах [1-5]. Ранее нами было показано, что модификация пористой структуры углеродного материала тонкими пленками электронопроводящих полимерных металлокомплексов с основаниями Шиффа (поли- $[\mathrm{M}(\mathrm{Schiff})])$ приводит к значительному увеличению удельной объемной емкости положительного электрода двойнослойного суперконденсатора, заполненного электролитом на основе ацетонитрила (AN), за счет вклада псевдоемкости полимера в общую емкость системы $[6,7]$. В состав литий-ионного суперконденсатора входят литийсодержащие электролиты на основе смеси органических растворителей (например, этиленкарбоната (ЕC) и диметилкарбоната (DMC)), традиционно использующиеся при изготовлении литий-ионного аккумулятора [3]. Недавно обнаруженная способность полимеров поли- $[\mathrm{M}(\mathrm{Schiff})]$ к протеканию обратимых редокс-процессов в литийсодержащих электролитах [8] делает перспективной попытку использования данных полимеров для увеличения емкости положительного электрода литий-ионного суперконденсатора и, следовательно, емкости всего устройства.

В настоящей работе были изготовлены прототипные ячейки литий-ионного суперконденсатора, содержащие положительный электрод на основе высокопористого углеродного материала, модифицированного полимерным комплексом никеля (II) с лигандом N,N'-2,3-диметилбутан-2,3-диил-бис(салицилиденимин) (поли-[Ni(Saltmen)]), и предварительно литированный отрицательный электрод. Экспериментальные характеристики разработанной системы были сопоставлены с параметрами аналогичных ячеек, содержащих немодифицированный полимером положительный электрод.

Положительные электроды размером $20 \times 20 \mathrm{~mm}$ были изготовлены из алюминиевой фольги, с одной стороны покрытой активным слоем (толщиной $70 \mu \mathrm{m}$ ) на основе углеродного материала с высокоразвитой поверхностью $\left(1700 \mathrm{~m}^{2} \cdot \mathrm{g}^{-1}\right)$ (EnerG2 Technologies Inc.). Синтез комплекса $[\mathrm{Ni}(\mathrm{Saltmen})]$ и последующая адсорбционно-электрохимическая модификация электродов его полимерной формой осуществлялись по описанным ранее методикам [7], в которые были внесены изменения, целью которых было достижение наиболее равномерного распределения полимера по толщине модифицируемого материала. В частности, полимеризация 
Процентное увеличение удельной объемной емкости прототипных ячеек литий-ионного суперконденсатора при модификации положительного электрода полимером поли-[Ni(Saltmen)]

\begin{tabular}{c|c}
\hline $\begin{array}{c}\text { Зарядное напряжение } U_{c h}, \mathrm{~V} \\
\left.\text { (заряд-разряд ячейки в диапазоне } 2.7 \mathrm{~V}-U_{c h}\right)\end{array}$ & $\begin{array}{c}\text { Увеличение удельной объемной } \\
\text { емкости ячейки, \% }\end{array}$ \\
\hline 3.85 & 31 \\
3.95 & 35 \\
4.05 & 39 \\
4.15 & 41 \\
4.25 & 49
\end{tabular}

адсорбированного на углеродном материале комплекса осуществлялась в $1 \mathrm{M}$ растворе тетрафторобората тетраэтиламмония $\left(\mathrm{Et}_{4} \mathrm{~N}\right) \mathrm{BF}_{4}$ (Merck) в $\mathrm{AN}$ (Криохром) в режиме гальваностатической поляризации электрода при плотности тока $25 \mathrm{~mA} \cdot \mathrm{cm}^{-2}$ (здесь и далее в расчете на геометрическую площадь электрода) до $1.3 \mathrm{~V}$ и далее в режиме потенциостатической поляризации при $1.3 \mathrm{~V}$ в течение $100 \mathrm{~s}$ (здесь и далее потенциалы приведены относительно хлоридсеребряного электрода, заполненного насыщенным водным раствором хлорида натрия). Исследование емкостных характеристик электродов проводилось в $1 \mathrm{M}$ растворе гексафторофосфата лития $\mathrm{LiPF}_{6}$ (Aldrich) в смеси EC/DMC в соотношении 1:1 по массе методом гальваностатического заряда-разряда при плотности тока $2.5 \mathrm{~mA} \cdot \mathrm{cm}^{-2}$ в интервале $0-1.3 \mathrm{~V}$. Электрохимические измерения проводились по трехэлектродной схеме (с заданием потенциала электрода) в герметичной электрохимической ячейке, содержащей вспомогательный электрод из нанопористого углеродного материала, емкость которого в 3 раза превышала емкость рабочего электрода. В качестве электрода сравнения использовался неводный электрод MF-2062 (BASi) - $0.005 \mathrm{M}$ $\mathrm{Ag}^{+} / \mathrm{Ag}$ в $0.1 \mathrm{M}\left(\mathrm{Et}_{4} \mathrm{~N}\right) \mathrm{BF}_{4} / \mathrm{AN}$ (потенциал относительно указанного выше хлоридсеребряного электрода $+0.3 \mathrm{~V})$.

Структурные особенности электродов были исследованы методами сканирующей электронной микроскопии (SEM) и энергодисперсионной спектрометрии (EDS) с использованием микроскопа Carl Zeiss EVO 40 (Германия).

Для создания прототипных ячеек подготавливалась электродная сборка, состоящая из положительного электрода, отрицательного электрода и дополнительного (расходуемого) литиевого электрода, разделенных пористым полиэтиленовым сепаратором Celgard K2045 (Celgard, США) толщиной $20 \mu \mathrm{m}$. Отрицательный электрод размером $20 \times 20 \mathrm{~mm}$ был изготовлен из углеродного материала Carbotron PJ (Kureha) методом намазки с 4\% LA133 (Chengdu Indigo) в качестве связующего. Литиевый электрод аналогичного размера представлял собой литиевую фольгу, напрессованную на медную сетку. Электродная сборка помещалась в конверт из ламинированной алюминиевой фольги, который заполнялся коммерческим электролитом ТC-918 (Tinci, КНР) - 1 М раствор $\mathrm{LiPF}_{6}$ в смеси EC/PC/DEC/EMC (этиленкарбо- нат, пропиленкарбонат, диэтилкарбонат, этилметилкарбонат) - и герметично запаивался. Электрохимические измерения выполнялись по двухэлектродной схеме (с заданием напряжения ячейки) методом гальваностатического заряда-разряда. На первом этапе осуществлялось предварительное литирование отрицательного электрода [3] методом заряда до $0.15 \mathrm{~V}$ токами $0.25,0.125$, $0.0625 \mathrm{~mA} \cdot \mathrm{cm}^{-2}$ (в расчете на геометрическую площадь электродной сборки). Далее проводились емкостные испытания ячеек при плотности тока $2.5 \mathrm{~mA} \cdot \mathrm{cm}^{-2}$ в интервале напряжений от $2.7 \mathrm{~V}$ до $U_{c h}$, значение которого варьировалось от 3.85 до $4.25 \mathrm{~V}$. Ресурсные испытания осуществлялись при плотности тока $1 \mathrm{~mA} \cdot \mathrm{cm}^{-2}$.

Процентное увеличение удельной объемной емкости (наиболее практически значимой характеристики литийионного суперконденсатора в свете его потенциального применения в портативных устройствах [9]) вследствие модификации оценивалось по формуле

$$
\left(\left(\Delta t_{2}-\Delta t_{1}\right) / \Delta t_{1}\right) \cdot 100 \%
$$

где $\Delta t_{2}-$ время разряда системы, модифицированной полимером, $\Delta t_{1}$ - время разряда немодифицированной системы (электрода или прототипа). Методика расчетов основывалась на том, что полимермодифицированные и исходные электроды имели одинаковую площадь и толщину, а прототипные ячейки на их основе - одинаковый объем. Разрядная емкость ячеек рассчитывалась по формуле

$$
C=I \Delta t
$$

где $I-$ ток разряда, $\Delta t-$ время разряда. Сопротивление ячеек рассчитывалось по формуле

$$
R=\Delta U / I
$$

где $\Delta U-$ величина начального падения напряжения при разряде.

Электрохимические измерения индивидуальных электродов проводились с помощью потенциостата-гальваностата Элинс Пи-50PRO3 (Россия). Для тестирования прототипов использовался стенд CT-3008W (Neware, КНР). Все эксперименты, за исключением испытаний прототипных ячеек, осуществлялись в перчаточном боксе в атмосфере сухого аргона. 

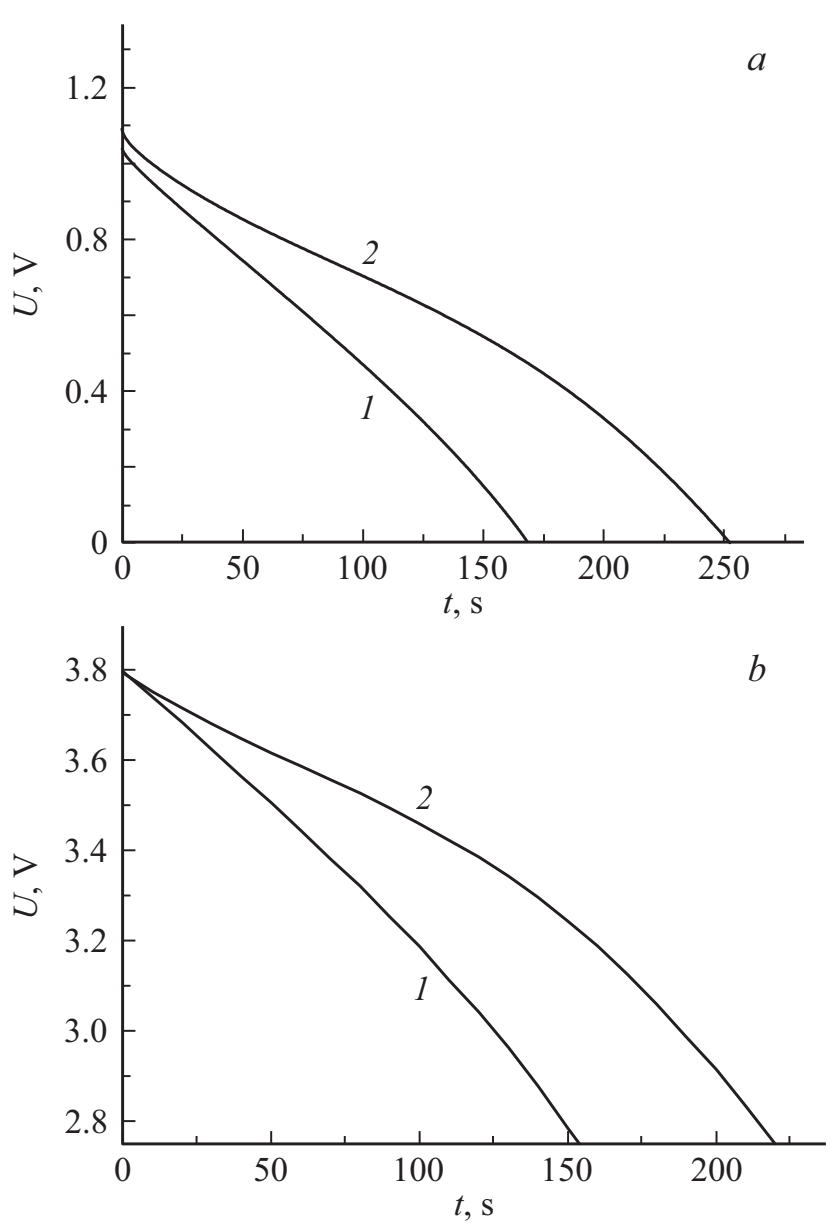

Рис. 1. Кривые разряда, полученные в гальваностатическом режиме при плотности тока $2.5 \mathrm{~mA} \cdot \mathrm{cm}^{-2}$ для немодифицированного (1) и полимермодифицированного (2) электрода (a), а также прототипных ячеек с немодифицированным (1) и полимермодифицированным (2) положительным электродом (b).

На рис. 1, a показаны кривые гальваностатического разряда электрода, модифицированного полимером поли- $[\mathrm{Ni}($ Saltmen $)]$, и немодифицированного электрода в литийсодержащем электролите. Разрядная кривая немодифицированного электрода имеет линейный характер, что указывает на то, что основным протекающим процессом является разряд двойного электрического слоя, формирующегося на поверхности углеродного материала при заряде. В случае полимермодифицированного электрода нелинейность разрядной кривой свидетельствует о протекании в системе псевдоемкостных (фарадеевских) процессов с участием полимерного металлокомплекса. Вклад псевдоемкости в общую емкость электрода наиболее значителен в диапазоне потенциалов 0.5-1.3 V, в целом совпадающем с диапазоном потенциалов редокс-процессов в полимере поли-[Ni(Saltmen)] [7]. Характер разрядной кривой в области потенциалов 0-0.5 V указывает на то, что модификация углеродного материала полимером не приводит к уменьшению двойнослойной емкости последнего. Удельная объемная емкость модифицированного электрода на 51\% превысила значение этого параметра для немодифицированного образца. Такое значительное увеличение емкости, вероятно, связано с характером распределения веществамодификатора в пористой углеродной матрице, достигнутым при использовании выбранного режима нанесения полимерного покрытия на углеродный материал.

Исследование изготовленных электродов методами SEM и EDS показало, что полимермодифицированный и немодифицированный электроды имеют сходную пористую структуру и рельеф поверхности. В модифицированном образце внутренняя поверхность углеродного материала покрыта полимерным слоем. Полимер относительно равномерно распределен по объему электрода и, обладая проницаемой для ионов и растворителя структурой, выстилает поры углеродного материала, но не блокирует их. Это создает благоприятные условия для проникновения в поры электролита и осуществления
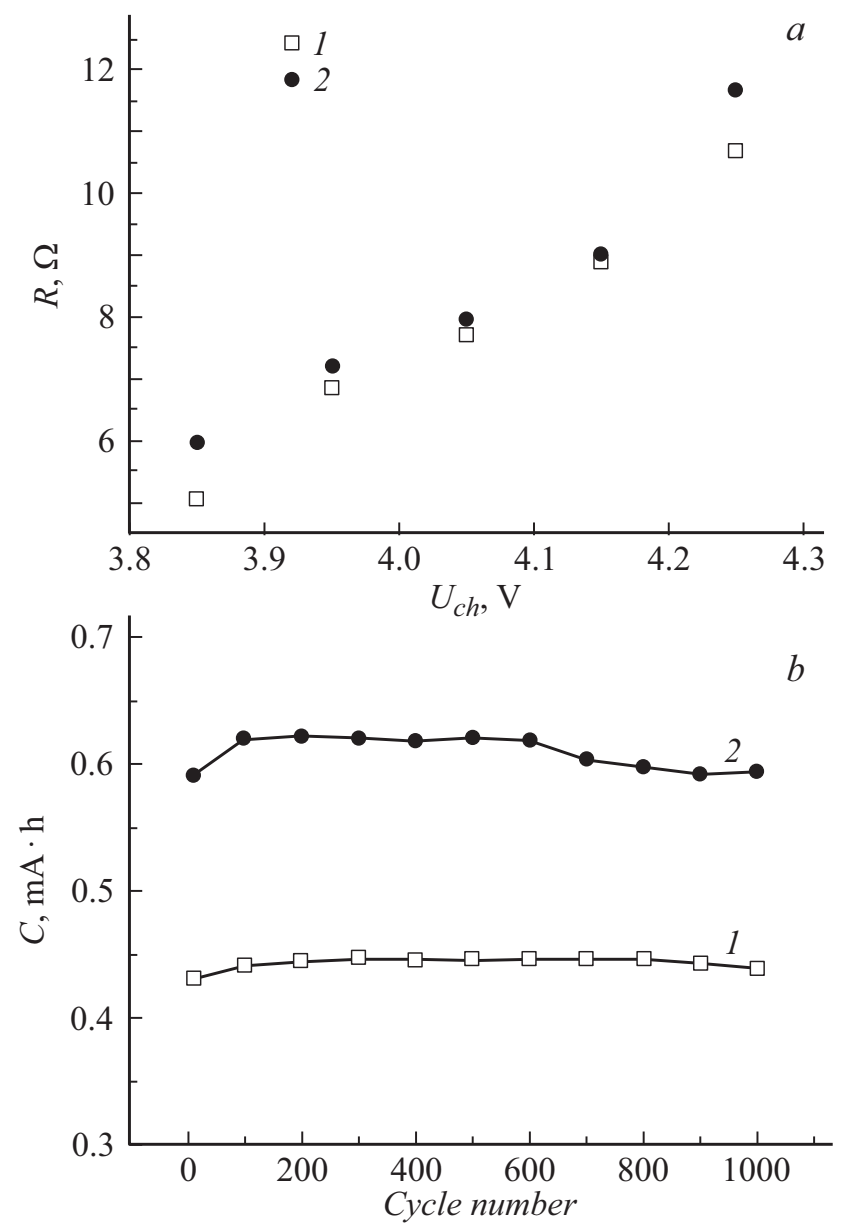

Рис. 2. $a-$ зависимость сопротивления от зарядного напряжения для прототипных ячеек с немодифицированным (1) и полимермодифицированным (2) положительным электродом; $b-$ зависимость разрядной емкости от количества циклов заряда-разряда в диапазоне $2.7-3.85 \mathrm{~V}$ для ячеек с немодифицированным (1) и полимермодифицированным (2) положительным электродом. 
как эффективного окисления-восстановления редоксактивного полимера поли- $\mathrm{Ni}(\mathrm{Saltmen})]$, так и зарядаразряда двойного электрического слоя. Благодаря этому емкость модифицированного электрода фактически представляет собой сумму двойнослойной емкости углеродного материала и псевдоемкости полимера.

Прототипные ячейки литий-ионного суперконденсатора с полимермодифицированным положительным электродом значительно превосходят по удельной объемной емкости прототипы, содержащие немодифицированный положительный электрод (см. таблицу). Разрядные кривые ячеек в диапазоне 2.7-3.85 V приведены на рис. 1, $b$ в качестве примера. Как и в случае индивидуальных электродов, нелинейность разрядной характеристики для ячейки с модифицированным положительным электродом отражает протекание псевдоемкостных процессов с участием полимера-модификатора. Количество электричества, запасаемое полимерными комплексами никеля с основаниями Шиффа при заряде, увеличивается с ростом глубины поляризации электрода [6-8]. Этим объясняется большее увеличение емкости ячейки с полимермодифицированным положительным электродом относительно емкости ячейки с немодифицированным положительным электродом при больших значениях зарядного напряжения (см. таблицу).

Оба типа прототипных ячеек характеризуются близкими значениями сопротивления (рис. 2,a). Несколько бо́льшие значения сопротивления системы с полимермодифицированным положительным электродом при зарядных напряжениях 3.85 и $4.25 \mathrm{~V}$, вероятно, связаны с более низкой проводимостью полимера при минимальной и максимальной степенях допирования соответственно.

В ресурсных испытаниях прототипы продемонстрировали хорошую стабильность электрохимических характеристик практически во всех диапазонах тестирования. Для обоих типов ячеек после 1000 циклов гальваностатического заряда-разряда значения разрядной емкости сохранялись на уровне не менее $95 \%$ от исходных. Сравнительные результаты ресурсных испытаний в диапазоне 2.7-3.85 V представлены на рис. 2, $b$ в качестве примера. Для обеих систем наблюдался некоторый рост первоначального значения емкости в течение первых 100 циклов работы, причем для ячеек с полимермодифицированным положительным электродом данный эффект оказался более выраженным. Увеличение разрядного напряжения до $4.25 \mathrm{~V}$ привело к значительному ухудшению стабильности емкостных характеристик обоих типов ячеек (разрядная емкость уменьшилась на $30 \%$ за первые 100 циклов), что наиболее вероятно связано с процессами окислительной деградации их компонентов.

Таким образом, в работе установлено, что модификация положительного электрода литий-ионного суперконденсатора проводящим полимером поли-[Ni(Schiff)] позволяет значительно увеличить удельную объемную емкость конденсатора по сравнению с исходной системой. Остальные практически значимые характеристики устройства при этом не ухудшаются, что делает перспективным использование предложенного подхода при разработке современных накопителей электрической энергии.

\section{Конфликт интересов}

Авторы заявляют, что у них нет конфликта интересов.

\section{Список литературы}

[1] Han P., Xu G., Han X., Zhao J., Zhou X., Cui G. // Adv. Energy Mater. 2018. V. 8. N 26. P. 1801243. DOI: $10.1002 /$ aenm. 201801243

[2] Gu H., Zhu Y.-E., Yang J., Wei J., Zhou, Z. // ChemNanoMat. 2016. V. 2. N 7. P. 578-587. DOI: $10.1002 / \mathrm{cnma} 201600068$

[3] Коштял Ю.М., Румянцев А.М., Жданов В.В. // Электрохимическая энергетика. 2015. Т. 15. № 3. С. 119-129.

[4] Liu C., Koyyalamudi B., Li L., Emani S., Wang C., Shaw L. // Carbon. 2016. V. 109. P. 163-172. DOI: 10.1016/j.carbon.2016.07.071

[5] Zhang J., Wang J., Shi Z., Xu Z. // Chin. Chem. Lett. 2018. V. 29. N 4. P. 620-623. DOI: 10.1016/j.cclet.2018.01.031

[6] Карушев М.П., Тимонов А.М. // ЖПХ. 2012. Т. 85. В. 6. C. $932-938$.

[7] Чепурная И.А., Логвинов С.А., Карушев М.П., Тимонов А.М., Малев В.В. // Электрохимия. 2012. Т. 48. № 5. C. 590-597.

[8] Eliseeva S.N., Alekseeva E.V., Vereshchagin A.A., Volkov A.I., Vlasov P.S., Konev A.S., Levin O.V. // Macromol. Chem. Phys. 2017. V. 218. N 24. P. 1700361. DOI: $10.1002 /$ macp.201700361

[9] Wu S., Zhu Y. // Sci. China Mater. 2017. V. 60. N 1. P. 25-38. DOI: 0.1007/s40843-016-5109-4 